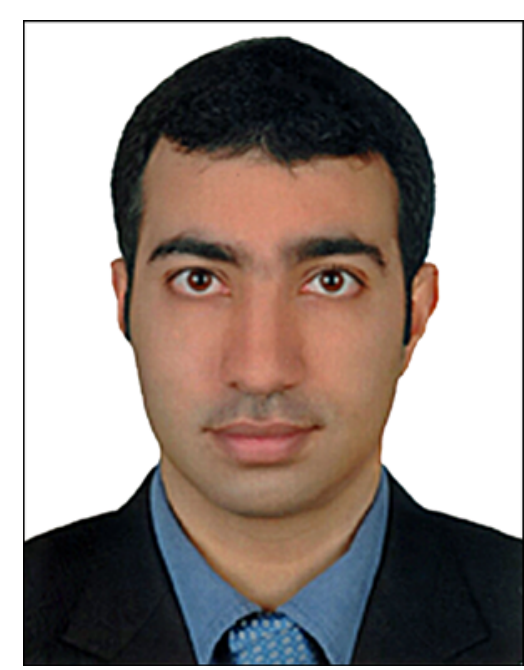

Haitham Jahrami, PhD

\section{Card sort methodology: An objective measure in rehabilitation research}

Card sort clinical tests such as the Wisconsin Card Sort Test and Activity Card Sort are well known in several clinical practices, including psychiatry, neurology, neuropsychology, and learning disabilities. However, card sort methodology is less famous as a research methodology. This editorial attempts to shed light on the novelty of the card sort methodology and its relevance to rehabilitation research.

Card sort methodology, commonly referred to as the card sort method, was introduced in 1935 by William Stephenson, a physicist and psychologist who served as the last assistant to Charles Spearman, the inventor of factor analysis [1]. In the card sort method, the researcher initially selects a set of items that are placed on individual cards. Collectively, the cards are called the card sort set and may be composed of a series of statements, words, pictures, instructing tasks, etc. [2]. Participants are then asked to sort the cards according to certain instructions such as approval versus disapproval, most like me versus least like me, or lowest versus highest priority.

Denzine provides the example of a researcher who is seeking student perceptions on the most desirable place to study in a university campus [3]. A card sort set would have to include all of the possible study locations (e.g., library, computer laboratory, student union); students would be asked to rank the cards using a desirability continuum. Thus, the middle cards are likely to contain the neutral views and extreme cards will contain the strongest views. The strongest views most likely contain the most important information. In questionnaire format, each question is independent of the others.

The card sort method involves an "ipsative" approach, which means that each item in the card sort set is dependent and interrelated. The participants are less likely to respond to an item that is inconsistent with the previous item because their choice is likely to be guided by the previous response. Denzine points out that in a forced sort situation, a normal statistical distribution will occur because of the ranking procedure that results in fewer cards being selected to represent the strongest held views of the participants. The method could therefore be used to understand relationships between items, to group items into categories, and to understand the subject's mental models of item organization.

Using the working example of patients' perceptions on the factors affecting quality of life, the major advantage of using the card sort method would be the generation of a systematic and comprehensive view of the patients' perceptions on these factors by examining how patients will subjectively rank the various factors, e.g., pain, activities of daily living, and leisure activities. Another advantage of this method is that it merges qualitative and 
quantitative methodologies, allowing a view of the data from a subjective perspective to be mathematically analyzed.

Traditional research methods look for objective measures that can be compared across subjects, such as skills, ability, knowledge, and the like. The card sort method, by contrast, deals with state of mind, for which the way the individual respondent orders stimuli is more important than how the respondent compares with others.

To conclude, card sort methodology could play a valuable role in many research problems in rehabilitation because it involves an interesting combination of quantitative and qualitative research methodologies.

\section{Haitham Jahrami, PhD}

Rehabilitation Services, Psychiatric Hospital, Ministry

of Health, Kingdom of Bahrain

Email: hjahrami@health.gov.bh

\section{REFERENCES}

1. Brewer GA, Selden SC, Facer RL II. Individual conceptions of public service motivation. Public Adm Rev. 2000;60:254-64. http://dx.doi.org/10.1111/0033-3352.00085.

2. Polit DF, Hungler BP. Nursing research: Principles and methods. 4th ed. Philadelphia (PA); Lippincott; 1991.

3. Denzine GM. The use of $Q$ methodology in student affairs research and practice [Internet]. Student Affairs Journal Online: 1998 Apr 3. [cited 2006 Mar]. Available from: http://www.sajo.org/

This article and any supplementary material should be cited as follows:

Jahrami H. Card sort methodology: An objective measure in rehabilitation research. J Rehabil Res Dev. 2012;49(2):vii-viii.

http://dx.doi.org/10.1682/JRRD.2012.01.0011

ResearcherID: H. Jahrami: A-4436-2012

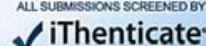

